\title{
Meninas Digitais - Regional Bahia: os primeiros bits
}

\author{
Juliana Maria Oliveira dos Santos, Ana Carolina Cerqueira Ferreira, Allan Thales \\ Ramos de Oliveira, Débora Abdalla Santos, Ecivaldo de Souza Matos
}

Departamento de Ciência da Computação - Universidade Federal da Bahia (UFBA) Grupo de Pesquisa e Extensão em Informática, Educação e Sociedade - Onda Digital Av. Adhemar de Barros, s/n - Ondina - CEP 40.170-110 - Salvador - BA - Brasil

\{julyms.85, cf.anacarolina\}@gmail.com, \{allan.thales, abdalla, ecivaldo\} @ufba.br

\begin{abstract}
This paper presents the first steps of the project "Meninas Digitais Regional Bahia" (Digital Girls - Chapter Bahia). It is presented some developed actions that can be applied by other organizations to further popularization of Computer Science among women. These strategies have regarded activities for men, in order to show that Computer Science must be for all, without gender distinction and without limitations of topics or disciplines.
\end{abstract}

Resumo. Este artigo apresenta os primeiros passos do Projeto Meninas Digitais - Regional Bahia, apontando ações desenvolvidas que podem ser adotadas por outras organizações e instituições para popularização da Computação entre as mulheres, considerando também a participação dos homens, de modo a mostrar que a Computação deveria ser um espaço para todos, sem distinção de gênero, raça, etnia e sem limitações de disciplinas elou temas.

\section{Introdução}

O Programa Meninas Digitais, chancelado pela Sociedade Brasileira de Computação (SBC), propõe ações voltadas a alunas do Ensino Médio/Tecnológico ou nos anos finais do Ensino Fundamental, para que conheçam a área de Informática, Computação e das Tecnologias da Informação e Comunicação (TIC), de forma a motivá-las a seguirem carreiras nessas áreas. O Programa aglutina iniciativas de outras instituições que passam a atuar como parceiras e multiplicadoras da proposta, de forma a disseminar esta ideia no território nacional [Figueiredo, Neto e Maciel, 2016].

Em maio de 2016, foi implantado o projeto de extensão Meninas Digitais Regional Bahia. Isso ocorreu no contexto da Universidade Federal da Bahia onde a taxa de mulheres nos cursos de graduação e pós-graduação em Computação é bastante reduzida, aproximando-se de 10\% no Bacharelado em Ciência da Computação, 10\% no Bacharelado em Engenharia da Computação, 16,7\% na Licenciatura em Computação, 17,8\% no Bacharelado em Sistemas de Informação, 22,4\% para o Mestrado em Ciência da Computação e 25\% no Doutorado em Ciência da Computação.

Este artigo apresenta os primeiros passos do Projeto Meninas Digitais Regional Bahia, sua metodologia e experiência, mostrando as ações desenvolvidas que podem ser adotadas por outras organizações e instituições para popularização da área de 
exatas, mais especificamente a Informática e Computação, para as mulheres.

\section{Concepção e Objetivos do Projeto}

O projeto nasceu como uma ação de extensão vinculada ao Programa Onda Digital (POD), um programa de extensão do Departamento de Ciência da Computação (DCC) da Universidade Federal da Bahia. Metodologicamente, escolhemos implantar o projeto em associação com o POD pelo fato de este já ser amplamente conhecido na comunidade acadêmica da UFBA e na cidade de Salvador/BA e região metropolitana. Isso permitiria sua articulação com outras instituições e coletivos. Isto porque espera-se nuclear diferentes propostas de fomente à participação feminina em Computação em uma regional, favorecendo a capilaridade do Programa Meninas Digitais no estado da Bahia.

Acredita-se que para incentivar a reflexão e mostrar que a Informática e Computação é para todas e todos, algumas ações afirmativas poderão ser necessárias, pois quando estamos desenvolvendo uma ação com base no princípio da equidade. Ainda que um de seus objetivos seja aumentar a participação de mulheres na computação, o projeto não tem o intuito de realizar apenas ações exclusivas para elas, mas fomentar o debate incluindo os homens, para que eles reflitam sobre o seu papel no processo de inclusão/exclusão de mulheres na IC. Isto por considerar que a IC é um espaço para todas e todos, sem distinção de gênero, raça/etnia, sem limitações de disciplinas e/ou temas.

Vale destacar que mesmo sendo concebido como um projeto de extensão, no projeto Meninas Digitais - Regional Bahia articula-se o ensino e pesquisa, por meio do estímulo à realização de trabalhos de conclusão de curso, projetos de pesquisa, dissertações de mestrado e teses de doutorado que abordam essa temática.

As ações desenvolvidas adotam os seguintes princípios:

- incentivo pelo exemplo: atividades e ações sendo apresentadas e desenvolvidas por mulheres;

- incentivo pela discussão: realização de ações como mesas redondas, palestras, dinâmicas, apresentação de vídeos ou dinâmica do preconceito $^{1}$ com o objetivo de trazer à tona a reflexão e discussão sobre a temática;

- incentivo pela implementação: atividades nas quais as participantes são motivados a desenvolver, implementar e/ou praticar conceitos abordados no estudo da computação.

\section{Os Primeiros Bits}

Dentre as ações já realizadas com foco na participação de mulheres na IC destacam-se:

- Mesa Redonda "Meninas Digitais: para além dos estereótipos (de gênero, raciais e étnicos) nas práticas sociais e educacionais": realizada no workshop anual do POD, em 2015, a mesa abordou a violação de direitos humanos e suas implicações, principalmente no tocante às relações raciais e de gênero, nos meios digitais e trouxe à tona a discussão sobre as influências dos estereótipos de gênero, raciais e éticos nos ambientes educacionais e nas relações de trabalho, com foco na

\footnotetext{
${ }^{1}$ Reafirmar preconceitos para a partir da discussão desconstruir conceitos estabelecidos.
} 
participação de mulheres nas ciências e com a apresentação de iniciativas de incentivo à participação de mulheres em cursos de Computação. Tivemos quatro convidadas que também falaram sobre seu dia a dia como uma mulher atuante na tecnologia.

- Workshop no Dia do Estudante: realizada em uma escola estadual para alunas e alunos do último ano do Ensino Médio, no dia do estudante no ano de 2016. Foram realizadas atividades diversas como a oficina envolvendo conceitos de ordenação e da tabela periódica (química) e a oficina sobre lixo eletrônico dividida em duas partes: teórica (riscos, formas de descarte adequado e legislação vigente) e prática (mini-oficina de recondicionamento e manutenção de computadores). Além disso, tivemos uma oficina de profissões da área de computação onde mulheres que já concluíram ou estavam cursando cursos de graduação em computação e tecnologia explicaram sobre seus cursos e sobre a carreira de mulheres na computação.

- Minicurso "Desenvolvendo Aplicativos para Android com o App Inventor": atividade integrante do workshop anual do POD no ano de 2016. Foi uma oficina com público misto (sendo $90 \%$ mulheres), onde as e os participantes foram apresentada(o)s aos conceitos básicos da ferramenta para o desenvolvimento de aplicativos e desenvolveram um aplicativo de Game Quiz, que utilizou recursos de lógica de programação, eventos de interface e comunicação com recursos de mídia do dispositivo.

- Mesa Redonda "A participação feminina na tecnologia": realizada no workshop anual do POD, em 2016. Esta mesa teve como objetivo ampliar o debate sobre a participação das mulheres no setor de tecnologia, trazendo três convidadas para compartilhar experiências pessoais e de projetos de incentivo à participação de mulheres na computação e o ciberfeminismo, apontando os entraves, desafios, influências, estratégias e resultados.

- Lançamento da fanpage do projeto de extensão: realizado no ano de 2017 com o objetivo de divulgar as ações realizadas, difundir a problemática e aglutinar pessoas com interesse no tema e ações - http://www.facebook.com/meninasdigitaisBA.

- Realização de Cursos de Iniciação à Programação de Computadores (CIProg) com turmas exclusivas para mulheres: as turmas exclusivas para mulheres têm o intuito de atrair esse o público ao universo da Informática e Computação.

Dentre as ações em andamento/planejamento e futuras podemos citar os seguintes eixos:

- Manual de Identidade Visual do Projeto

- Divulgação do Projeto

- carta de Apresentação, cartão de Visita e folder para potenciais parceiros e patrocinadores;

- apoio a projetos de outras instituições baianas;

○ participação em palestras e eventos;

- mapeamento das iniciativas baianas similares ou próximas.

- Acompanhamento e Avaliação das Ações de Extensão

- elaboração de estratégias de investigação das causas de evasão nos cursos;

- realização de grupos focais com as participantes das ações de extensão promovidas;

○ realização de grupos de avaliação das ações com as pessoas que atuaram como 
instrutoras, monitoras e coordenadoras;

- acompanhamento das alunas egressas dos cursos de extensão.

\section{- Realização de Ações}

- manutenção de contato com escolas, universidades, empresas e similares para realização de ações formativas, de divulgação de cursos da AIC, acolhimento de calouras, promoção de visitas técnicas;

- participação em encontros estudantis, feiras de profissões, semana de ciência e tecnologia e eventos similares onde possamos estar próximos de crianças e jovens;

○ realização de workshop anual do projeto.

\section{- Desenvolvimento de Materiais}

- desenvolvimento de cadernos de oficinas com opções diversas de temas e durações para aplicação em diversos ambientes;

- gamificação do ambiente virtual de aprendizagem Moodle, utilizado nos cursos de extensão regulares (carga horária mínima de 30 horas), com medalhas relacionadas à mulheres na história da computação em níveis local, nacional, regional e global.

\section{- Captação de Recursos}

- mapeamento das empresas e organizações do estado e do país que fomentam a participação de mulheres na tecnologia;

- elaboração de plano de patrocínio, incluindo modelo de carta de patrocínio, categorias e benefícios do patrocinador;

○ acompanhamento de submissão de propostas de ações junto a editais de fomento.

\section{Considerações Finais}

Esperamos que a experiência e metodologia do Projeto Meninas Digitais - Regional Bahia possa estimular outras organizações e instituições para popularização da área de exatas, mais especificamente a de Informática e Computação, para as mulheres. A boa aceitação das ações, repercussão na mídia e grande procura por cursos e atividades voltadas para mulheres apontam positivamente para continuidade e expansão das ações.

\section{Agradecimentos}

Agradecemos às/aos estudantes que colaboraram, colaboram e abraçam esta causa. Estendemos nossos agradecimentos à Pró-Reitoria de Extensão Universitária da UFBA e ao MEC, por meio do Edital Proext/MEC/SESu 2015, pelo apoio financeiro ao nascimento deste projeto.

\section{Referência}

Figueiredo, K. S., Neto, P. C. S., Maciel, C. (2016) "Meninas Digitais Regional Mato Grosso: Práticas Motivacionais no Ensino Médio para a Equidade de Gêneros nas Carreiras e Cursos de Computação e Tecnologias". X Women in Information Technology (WIT), Porto Alegre. In: Anais do XXXVI Congresso da Sociedade Brasileira de Computação. Porto Alegre, SBC. p. 2702-2705. 